University of Nebraska - Lincoln DigitalCommons@University of Nebraska - Lincoln

Faculty Publications from the Department of Electrical and Computer Engineering

Electrical \& Computer Engineering, Department of

2017

\title{
Formation of aggregated nanoparticle spheres through femtosecond laser surface processing
}

Alfred T. Tsubaki

Mark A. Koten

Michael J. Lucis

Craig Zuhlke

Natale J. Ianno

See next page for additional authors

Follow this and additional works at: http://digitalcommons.unl.edu/electricalengineeringfacpub Part of the Computer Engineering Commons, and the Electrical and Computer Engineering Commons

This Article is brought to you for free and open access by the Electrical \& Computer Engineering, Department of at DigitalCommons@University of Nebraska - Lincoln. It has been accepted for inclusion in Faculty Publications from the Department of Electrical and Computer Engineering by an authorized administrator of DigitalCommons@University of Nebraska - Lincoln. 
Authors

Alfred T. Tsubaki, Mark A. Koten, Michael J. Lucis, Craig Zuhlke, Natale J. Ianno, Jeffrey E. Shield, and Dennis R. Alexander 
Published in final edited form as:

Appl Surf Sci. 2017 October 15; 419: 778-787. doi:10.1016/j.apsusc.2017.05.094.

Copyright $\odot 2017$ Elsevier B.V

\title{
Formation of aggregated nanoparticle spheres through femtosecond laser surface processing
}

\author{
Alfred T. Tsubaki ${ }^{a},{ }^{,}$, Mark A. Koten ${ }^{b}$, Michael J. Lucis ${ }^{b}$, Craig Zuhlke $^{a}$, Natale lanno ${ }^{a}$, Jeffrey \\ E. Shield ${ }^{\mathrm{b}}$, and Dennis R. Alexander ${ }^{\mathrm{a}}$ \\ aDepartment of Electrical and Computer Engineering, University of Nebraska-Lincoln, $844 \mathrm{~N} 16$ th \\ St, Lincoln, NE 68588, USA \\ bDepartment of Mechanical and Material Engineering, University of Nebraska-Lincoln, $844 \mathrm{~N}$ 16th \\ St, Lincoln, NE 68588, USA
}

\section{Abstract}

A detailed structural and chemical analysis of a class of self-organized surface structures, termed aggregated nanoparticle spheres (AN-spheres), created using femtosecond laser surface processing (FLSP) on silicon, silicon carbide, and aluminum is reported in this paper. AN-spheres are spherical microstructures that are $20-100 \mu \mathrm{m}$ in diameter and are composed entirely of nanoparticles produced during femtosecond laser ablation of material. AN-spheres have an onionlike layered morphology resulting from the build-up of nanoparticle layers over multiple passes of the laser beam. The material properties and chemical composition of the AN-spheres are presented in this paper based on scanning electron microscopy (SEM), focused ion beam (FIB) milling, transmission electron microscopy (TEM), and energy dispersive x-ray spectroscopy (EDX) analysis. There is a distinct difference in the density of nanoparticles between concentric rings of the onion-like morphology of the AN-sphere. Layers of high-density form when the laser sinters nanoparticles together and low-density layers form when nanoparticles redeposit while the laser ablates areas surrounding the AN-sphere. The dynamic nature of femtosecond laser ablation creates a variety of nanoparticles that make-up the AN-spheres including Si/C core-shell, nanoparticles that directly fragmented from the base material, nanoparticles with carbon shells that retarded oxidation, and amorphous, fully oxidized nanoparticles.

\section{Keywords}

Femtosecond laser; Laser processing; Onion-like; Core-shell; Nanoparticle aggregates

\section{Introduction}

Femtosecond laser surface processing (FLSP) is a surface functionalization technique that alters the physical, chemical, mechanical, and electrical properties of a material in a single highly non-equilibrium processing step. It has been demonstrated that FLSP can be utilized to create a variety of unique self-organized surface micro/nanostructures on both metals and

\footnotetext{
Corresponding author. alfredtsubaki@ gmail.com (A.T. Tsubaki).
} 
semiconductors [1-8]. Due to their exotic surface properties, when compared to untreated surfaces, research efforts have been directed into further developing FLSP techniques. FLSP can be used to modify a wide range of surface properties, which include producing surfaces that exhibit wide-band optical absorption [6,9,10], enhanced heat transfer characteristics [11-13], and extreme wetting properties ranging from superhydrophilic $[14,15]$ to superhydrophobic $[1,16]$.

In recent years, FLSP research reported in the literature has focused on the formation and applications of three distinct surface structures[7,17-19], termed by Zuhlke et al. as nanoparticle covered pyramids (NC-pyramids) [20], below surface growth mounds (BSGmounds), and above surface growth mounds (ASG-mounds) [21-24]. Every group of researchers have termed these structures differently. For example, Ling et al. refers to these structures as ellipsoidal cones, columnar structures, and chaotic structures[25] while Kam et al. refers to them collectively as cones [26]. NC-pyramids, BSG-mounds, and ASG-mounds each form through a unique balance of preferential valley ablation, redeposition of ablated material, and hydrodynamic effects of the laser induced surface melt [2,21,23,24,27-29]. The morphology of the structures produced through FLSP is dependent on the laser processing parameters, for example, the number of laser pulses and the fluence of the pulses. Zuhlke et al. demonstrated that using certain FLSP parameters, nanoparticles created from femtosecond laser ablation of aluminum (Al) can self-assemble and aggregate into onionlike structures. The self-assembled, onion-like nanoparticle agglomerates are significantly different than the FLSP surface structures previously mentioned and have been thus termed aggregated nanoparticle spheres (AN-spheres) [5]. AN-spheres have potential applications in energy storage [30,31] and drug delivery [30,32]. Understanding the formation processes, and the chemical and physical make-up of AN-spheres allows these structures to be tailored for specific applications.

When high intensity ultrashort laser pulses interact with a material, a shockwave caused by material expansion ejects constituent particles from the substrate when processing in a background gas. The ejected material consist of a mixture of neutral nanoparticles, free electrons, and ionized atoms that form a laser-induced plasma plume [33]. The nanoparticles in the plasma plume are very reactive due to high surface energy, large surface area, and charge causing many to oxidize when processing is carried out in an oxygen-rich environment $[6,30,34]$. Maisterrena-Epstein et al. concluded that metals oxidize, to different degrees, with a strong dependence on laser fluence [35]. After the initial shockwave, a fraction of the ejected materials aggregate, forming clusters that condense on the sample in the form of nanoparticles. The size, composition, and density of the nanoparticles are a function of the material, processing parameters (i.e., laser fluence and number of laser pulses), and processing environment (i.e., reactant gas/liquid, pressure, etc.) [6,36]. In most cases, the nanoparticles blanket the self-organized microstructures created during FLSP similar to the nanoparticle films created by pulsed laser deposition $[37,38]$.

Zuhlke et al. suggested that $\mathrm{AN}$-spheres preferentially grow on intrinsic material defects within the laser processed area [5]. Defects can include those in the base material, or lattice, and surface defects induced through initial laser pulses. AN-spheres that begin the nucleation process early will experience more preferential redeposition events. Thus, the 
earlier an $\mathrm{AN}$-sphere nucleates the larger the final diameter will be. It has also been demonstrated in the literature that the number of nanoparticles produced during ablation from femtosecond pulses is a function of both pulse fluence and processing environment [32,39-43]. Therefore, it is expected that fluence and processing environment will affect the thickness of the onion-like layers. In this paper, the formation processes of self-assembled AN-spheres on silicon ( $\mathrm{Si})$, silicon carbide $(\mathrm{SiC})$, and aluminum $(\mathrm{Al})$ are presented based on in-depth compositional analysis using advanced electron microscopy analytical tools not previously applied to AN-spheres. This is the first time AN-spheres, developed through FLSP, have been reported on any material other than Al.

\section{Experiment}

The femtosecond laser used in this work was a Spectra Physics, Spitfire system capable of producing $1 \mathrm{~mJ}, 80 \mathrm{fs}$ pulses at a $1 \mathrm{kHz}$ repetition rate with a central wavelength of $800 \mathrm{~nm}$. A Frequency Resolved Optical Gating (FROG) instrument from Positive Light (Model 8-02) monitors the pulse length and chirp of the pulses. Nanomotion II translation stages (Melles Griot) with three axes of motion, control the position of the sample relative to the focal volume of the laser beam. Laser pulses were focused using a parabolic mirror with a protected silver coating and focal length of $152.4 \mathrm{~mm}$ (Thorlabs MPD169-P01). A halfwaveplate and polarizer combination was used to control the pulse energy. The spot size of the focused pulses on the sample surface was adjusted by varying the distance between the parabolic mirror and the sample surface. A schematic of the experimental setup of the laser system is included in Fig. 1. The energy per unit area (fluence) and the number of laser pulses per unit area incident on the sample were controlled by adjusting the speed of the stages, pitch between raster passes, pulse energy, and spot size. Fig. $1 \mathrm{~b}$ is a diagram of the standard programmed raster path for the stage system used to produce FLSP samples.

The AN-sphere samples were imaged using both a Phillips XL-30 SEM and an FEI Helios 660 Nanolab DualBeam FIB/SEM. AN-spheres were cross-sectioned and prepared for TEM imaging using a standard lift-out procedure with the Helios 660 FIB/SEM. An FEI Tecnai Osiris (scanning) transmission electron microscope (S/TEM) operating at $200 \mathrm{kV}$ was used to study the internal microstructure and chemical makeup of the AN-spheres with high spatial resolution. Energy dispersive x-ray spectroscopic (EDX) analysis of the AN-spheres was performed in both the FIB/SEM and the S/TEM in scanning mode. The crystal structure of the AN-spheres was investigated using high-resolution (HR) TEM and selected area electron diffraction (SAD). Elemental maps were collected using EDX in STEM mode. These maps were quantified by a standardless, PhiRhoZ peak-fitting method after performing background subtraction in the Esprit software package issued by Bruker Corp. Finally, line scan data were extracted from the drift-corrected maps, and the radial dependence of the stoichiometry of the AN-spheres was analyzed.

This paper explores the morphology and chemical composition of AN-spheres produced on three different materials. AN-spheres were produced on phosphor-doped n-type silicon (111) (Monsanto), single crystal n-type 4H-polytype silicon carbide (SiCrystal), and $2024 \mathrm{~T} 3 \mathrm{Al}$ (McMaster Carr). The analysis of the AN-spheres is presented from a macroscale analysis of the outside of the structures and works inwards towards microscale analysis of the internal 
structure followed by atomic scale analysis of nanoparticles that make-up the aggregates. First, the structure and morphology of the AN-spheres is presented using electron microscopy images along with associated SAD patterns to determine the crystal structure. Then chemical analysis is presented to provide the overall composition of the AN-spheres followed by quantified line scans across the various boundaries within the cross-section. Additional STEM elemental maps and quantified line scans are included for unique nanoparticles embedded in the SiC AN-sphere. Finally, the formation mechanisms are discussed focusing on the results of the cross-sectional analysis.

The AN-spheres studied in this paper were created using the processing parameters outlined in Table 1. All samples were processed in open atmosphere. Since each material has different material properties, and therefore reacts differently to the incident pulses, the fluence and number of laser pulses per unit area necessary to create $\mathrm{AN}$-spheres varies between samples.

\section{Results and discussion}

\subsection{Structure and morphology of AN-spheres}

3.1.1. Scanning electron microscopy-The AN-sphere structures reported in this paper are spherical aggregates of nanoparticles produced during FLSP. The AN-spheres are spherical or hemispherical in nature, typically with diameters of a few to tens of microns, with nanoscale surface features (Fig. 2).

The internal structure consists of an onion-like morphology of a series of concentric rings. Each ring is composed entirely of nanoparticles, with varied density of nanoparticles providing contrast between individual rings. The internal structure of an $\mathrm{AN}$-sphere on $\mathrm{Si}$, which has been cross-sectioned using FIB milling, is included in Fig. 3. AN-spheres on Al and $\mathrm{SiC}$ have a similar internal structure, as discussed in further detail below.

The distinct regions, or rings, visible in Fig. 3 form with each raster scan pass of the laser. The number of rings within an $\mathrm{AN}$-sphere roughly corresponds to the number of line scans that pass over that AN-sphere. After a single pass of the laser, a layer of nanoparticles deposits on the sample from the plume of material ejected during ablation. The growth of layers on an AN-sphere occurs when the laser beam is rastered across the sample and the layers consecutively form on top of one another. Intuitively, the spherical nature results from the nanoparticles aggregating to a surface point defect rather than evenly dispersing across the rastered area. With each pass, the AN-spheres increase in size as the ablated plume of nanoparticles aggregate on the surface. The number of shells is related to the number of passes of the laser beam [5].

The rings of the AN-sphere in Fig. 3 are composed of alternating light and dark regions due to a variation of nanoparticle density and/or composition. When the laser passes over an ANsphere, the outer most layer of nanoparticles sinter together, and areas of high-density form. Areas of low material density occur when nanoparticles redeposit on the AN-sphere while the laser is ablating adjacent areas of the sample. The number of rings of the AN-sphere in Fig. 3 corresponds approximately to the number of line scans of the raster scan pattern used 
in producing the $\mathrm{AN}$-sphere. The $\mathrm{AN}$-sphere in Fig. 3 has fourteen ring pairs (one light and one dark ring). The processing parameters to create this particular AN-sphere include a laser spot diameter of $228.7 \mu \mathrm{m}$ and a pitch of $15 \mu \mathrm{m}$. The number of rings corresponds to the laser passing over a single point in the raster fifteen times. The one ring discrepancy in the number of laser passes and the resulting number of rings is due to the Gaussian shape of the beam; there may not be enough energy on the leading and lagging edges of the beam to sinter the nanoparticles and create the additional ring. It is also possible that the $\mathrm{AN}$-sphere did not nucleate during the first pass of the laser.

As a means to visualize how the $\mathrm{AN}$-spheres are attached to the sample surface, a sample covered with AN-spheres was placed in an ultrasonic bath filled with distilled water. During the ultrasonic bath, some of the $\mathrm{AN}$-spheres are removed but the ring structure remains on the sample surface. An example of this residual ring structure is visible in Fig. 4, which includes an SEM image of a Si AN-sphere surface after fifteen minutes in an ultrasonic bath. A dome is observed at the core of the AN-sphere in Fig. 4. This dome is the initial nucleation site covered by the first, high-density layer of nanoparticles (see Section 3.3).

For each of the materials reported on in this paper, an AN-sphere was cross-sectioned using FIB milling and lifted out for TEM analysis. Bright field (BF) TEM images, where contrast is primarily due to varying diffraction conditions of the crystals, of the AN-sphere crosssections are shown in Fig. 5. The dark regions of Fig. 5 are attributed to a higher density of nanoparticles with respect to the bright regions.

Intermittent lattice fringes are visible in the BF-TEM images of nanoparticles for the $\mathrm{Si}$ and Al samples (Fig. 6). Distinct lattice fringes of the Si surrounded by an amorphous shell can be seen in the TEM image included Fig. 6(a). The silicon core-shell nanoparticle is the result of surface oxidation during the rapid heating and cooling cycles induced by a femtosecond laser pulse. Due to the core-shell structure, this feature suggests that the nanoparticles begin as pure silicon but oxidize at the surface while in the ablation plume. Although the included BF-TEM image for the SiC AN-sphere is at a lower magnification (Fig. 6(c)), making any possible lattice fringes difficult to distinguish, no lattice fringes were observed during TEM analysis. The lack of lattice fringes in Fig. 6(c) suggests a lack of crystallinity on the SiC AN-sphere. The SAD patterns in Section 3.1.2 provide quantitative data indicating the $\mathrm{SiC}$ $\mathrm{AN}$-sphere is made of amorphous nanoparticles. The $\mathrm{Al}$ nanoparticles were almost completely amorphous but a few lattice fringes were intermittently located in the TEM image (Fig. 6(d)). Hydrodynamic effects induced by laser sintering caused the irregular shape of the $\mathrm{SiC}$ and $\mathrm{Al}$ nanoparticles.

3.1.2. SAD pattern of AN-spheres-In order to quantify the crystallinity of the $\mathrm{Si}$ and $\mathrm{Al}$ nanoparticles and the amorphous nature of the $\mathrm{SiC}$ nanoparticles depicted in Fig. 6, SAD patterns for $\mathrm{Si}, \mathrm{SiC}$, and $\mathrm{Al}$ were collected and are presented in Fig. 7. For $\mathrm{Si}$, the diffraction rings indexed well to the $\{111\},\{220\},\{311\}$ and $\{400\}$ planes of diamond cubic $\mathrm{Si}$ with a lattice parameter of $5.43 \AA$ [44]. The crystalline phase change of the Si nanoparticles stems from the large temperature and pressure gradients caused by the femtosecond pulses $[45,46]$. 
There were no sharp diffraction maxima in the SAD pattern for the SiC, as seen in Fig. 7(b), indicating that these nanoparticles are amorphous. The $\mathrm{Al}$ nanoparticles have clear rings corresponding to the $\{200\}$ and $\{220\}$ planes of fcc $\mathrm{Al}(\mathrm{a}=4.05 \AA$ [47]) as shown in Fig. 7 (c). The $\{111\}$ is not visible because it is hidden in the bright signal from the incident beam. This is consistent with our visual analysis of the HR-TEM images of the nanoparticles in Fig. 6.

\subsection{Chemical analysis of AN-spheres}

3.2.1. Energy dispersive X-ray spectroscopy-EDX point analysis was performed on the surface of each AN-sphere at $20 \mathrm{keV}$. The $\mathrm{AN}$-spheres on both the $\mathrm{Si}$ and $\mathrm{SiC}$ have an overall composition of $\mathrm{SiO}_{2}$. The $\mathrm{SiC}$ AN-sphere studied here contains a relatively small amount of carbon and a majority of the individual nanoparticles contained no carbon. Based on the ratio of $\mathrm{Al}$ to $\mathrm{O}$ in the $2024 \mathrm{~T} 3 \mathrm{Al}$ sample, the nanoparticles are predominately $\mathrm{Al}_{2} \mathrm{O}_{3}$. The small percentage of carbon present in each material can be partially attributed to organic contaminants in the ambient air [15] that attach to the surface between sample processing and analysis. The EDX results are summarized in Table 2.

\subsubsection{Scanning transmission electron microscopy elemental mapping-In} order to gain insight into the elemental make-up at different depths within the AN-spheres, quantified EDX line scans were taken across multiple rings of the AN-spheres on $\mathrm{Si}, \mathrm{SiC}$, and Al. The resulting data are included in Figs. 8-10, respectively. Fig. 8(c) is a high angle annular dark field (HAADF) STEM image, which, unlike the bright field technique, collects the scattered beam to create an image with atomic number contrast. The green arrow in Fig. $8 \mathrm{c}$ indicates the direction of the line scan and is directly related to the yellow line in Fig. 8(a). There is a distinct difference in the composition of silicon and oxygen in the different layers of Fig. 8. An EDX line scan taken from the center of the sphere out toward the surface shows that the composition alternates between successive layers of $\mathrm{Si}$ and $\mathrm{SiO}_{2}$ with varying degrees of surface oxidation. The Si appears to form in the high-density regions, while the $\mathrm{SiO}_{2}$ forms in the low-density regions. One explanation is that the nanoparticles in the lowdensity regions are more exposed to atmosphere, which allows an increase in surface oxidation.

A quantified EDX line scan of the $\mathrm{SiC}$ AN-sphere is included in Fig. 9. Carbon is included in this analysis because of its signifi-cant contribution to the base material. Fig. 9(c) is the HAADF-STEM image of the SiC AN-sphere. In a study by Harris et al. [48], SiC was processed using a $\mathrm{KrF}$ laser and resulted in an oxidized surface with little to no base material remaining. Our results are consistent with Harris et al. Fig. 9 indicates that little carbon remains on the oxidized surface after FLSP. The quantified TEM line scan and EDX results are in good agreement that the sample composition is $\mathrm{SiO}_{2}$.

The large variations in composition seen between the rings of the Si sample are not as pronounced on the $\mathrm{SiC}$ sample. This may be a result of larger fluence used to produce the $\mathrm{SiC}$ AN-spheres, causing the nanoparticles to oxidize more thoroughly. Vorobyev and Guo studied the chemical energy released during oxidation of Al caused by femtosecond laser ablation. They concluded that an increase in fluence caused an increase in released chemical 
energy and an increase in Al oxidation [49]. Another possible explanation is that FLSP causes the $\mathrm{Si}-\mathrm{C}$ bonds to break when the material is ablated. The enthalpy of a $\mathrm{SiC}\left(\Delta_{\mathrm{f}} \mathrm{H}^{\circ}=\right.$ $-71.55 \mathrm{~kJ} / \mathrm{mol}$ ) is significantly less negative (less stable) than $\mathrm{SiO}_{2}\left(\Delta_{\mathrm{f}} \mathrm{H}^{\circ}=-905.49 \mathrm{~kJ} / \mathrm{mol}\right)$ which makes the formation of $\mathrm{SiO}_{2}$ more favorable than $\mathrm{SiC}$ in an oxygen-rich environment.

The Al AN-sphere quantified TEM line scan data are presented in Fig. 10. These ANspheres have the least amount of variation between the light and dark rings of the BF image. Throughout the cross-section, the maximum fluctuation of aluminum and oxygen is $\pm 6 \%$. Similar to the $\mathrm{Si} \mathrm{AN}$-spheres, the $\mathrm{Al} \mathrm{AN}$-spheres have oxygen peaks located on the low density rings of the HAADF image, as seen by comparing Fig. 10(b) and (c). The reduction in chemical variation across the rings are suspected to be the result of two factors. First, a relatively high fluence (compared to $\mathrm{Si}$ ) results in more thorough oxidation of the nanoparticles. Second, the enthalpy of aluminum oxide $\left(\Delta_{\mathrm{f}} \mathrm{H}^{\circ}=-1675.69 \mathrm{~kJ} / \mathrm{mol}\right)$ is more negative than silicon oxide $\left(\Delta_{\mathrm{f}} \mathrm{H}^{\circ}=-905.49 \mathrm{~kJ} / \mathrm{mol}\right)$ which causes aluminum oxides to form more readily than silicon oxides.

3.2.3. Chemical analysis of SiC nanoparticles-Results from the EDX analysis and quantified EDX line scan data of the $\mathrm{SiC}$ samples indicated that there was very little carbon present in these AN-spheres. This result is consistent with Harris et al. who concluded in their study of $\mathrm{SiC}$ that nearly no carbon was present in the oxidized $\mathrm{SiC}$ after laser processing [48]. The small amount of carbon found in the EDX analysis was initially attributed to the interaction of the post-processed sample with ambient air. Upon further investigation, particles were found in the AN-sphere that did not coincide with the expected $\mathrm{SiO}_{2}$ nanoparticle composition. Fig. 11 is a STEM map of one such particle marked with an oval in the figure. The STEM elemental maps clearly show the particle is composed of silicon and carbon. The irregularity of the particle shape suggests that it was ejected during the ablation process through fragmentation and did not vaporize and condense onto the surface.

There are additional smaller spherical nanoparticles dispersed throughout the AN-sphere that include carbon (see Fig. 11). Further investigation of the spatial distribution of elements within one of these particles is shown in the STEM elemental map included in Fig. 12. This particular particle has a carbon shell with an interior composed of silicon and nearly no oxygen. Yamaguchi et al. concluded that femtosecond irradiation of crystalline SiC caused amorphous silicon and amorphous carbon to form at fluences above the damage threshold [45]. The same group also suggested that atomic diffusion occurs [50], which explains the carbon shell surrounding the nanoparticle.

A quantified EDX line scan across this particle is included in Fig. 13. The oxygen content decreases from the edges to the center of the particle. Although it is unknown if the oxygen is located within the particle, it is theorized that the oxygen is located on the surface and the curvature of the particle results in a higher level of oxygen on the edges compared to the center. Similar curvature effects have been observed in other core-shell nanoparticles [51]. 


\subsection{AN-sphere formation}

Based on analysis of the $\mathrm{AN}$-spheres on $\mathrm{Si}, \mathrm{SiC}$, and $\mathrm{Al}$ and a review of the literature as discussed throughout this paper, we present here a summary of the formation processes for $\mathrm{AN}$-spheres. AN-spheres begin the formation process when nanoparticles begin to aggregate on a defect in the base material. After successive lines scans of a raster, layers build up from the defect causing distinct rings to form. Preferential redeposition and self-assembly into a spherical structure are believed to be a product of surface charging and diffraction effects. The charged surface attracts charged and neutral particles through electrophoresis and dielectrophoresis. At the base of the AN-sphere, an increased intensity due to diffraction effects leads to high ablation rates which cause the spherical shells to form [5]. With each laser pass, nanoparticles sinter together forming regions of higher density with respect to the purely aggregated nanoparticle rings. This repeated process results in distinct concentric rings.

The following discussion of the formation mechanisms of AN-spheres focuses mainly on $\mathrm{Si}$ due to the most distinct high and low density rings. The EDX area scan on the external surface of the AN-sphere indicates that the overall composition of is $\mathrm{SiO}_{2}$, while the quantified line scans reveal that the composition varies across the rings depending on the density of nanoparticles within the ring. Nanoparticles primarily condense out of the ablation plume and redeposit onto the surface of the substrate, although, a small fraction of the nanoparticles also arise from direct fragmentation of the base material. Fragmentation is most apparent in the presence of carbon within some nanoparticles in the SiC AN-spheres. When the laser interacts with the nanoparticles (i.e. the laser beam is illuminating the particles), they are sintered together into a solid nucleus that becomes the core of these multishell structures. The cross-sectional TEM specimens show that the core is composed of the sparsely packed $\mathrm{SiO}_{\mathrm{x}}$ variety, where $2<\mathrm{x}<4$. This suggests that the core of the ANsphere is made up of an agglomerate of nanoparticles. Since it is intuitive that the laser melts and sinters the nanoparticles into a more solid structure, the dense shells that form must be created by the laser passing over these nanoparticles. This causes the dark regions of the BF image (Fig. 5) to form, which indicates an area of high density. The overall surface area-tovolume ratio of the nanoparticles decreases when they are sintered together, causing a net decrease in surface oxidation. This is supported by the dark, high-density regions of Fig. 5 having a composition comparable to $\mathrm{Si}$ and the bright, low-density regions being comprised of $\mathrm{SiO}_{2}$. In both cases, the nanoparticles have different degrees of surface oxidation causing a variation in the silicon-to-oxygen ratio.

The large variations in chemical composition across the light and dark rings of $\mathrm{Si}$ is not as pronounced on the $\mathrm{SiC}$ and $\mathrm{Al}$ samples. A major difference between these samples is the uniform composition of the nanoparticles observed across the ring boundaries on $\mathrm{SiC}$ and $\mathrm{Al}$ but not on $\mathrm{Si}$. Since the $\mathrm{SiC}$ and $\mathrm{Al}$ nanoparticles completely oxidized, there is little variation in chemical composition. The trivial differences between the light and dark rings of the $\mathrm{SiC}$ and $\mathrm{Al}$ samples are due to the laser processing parameters. Fluences of $2.26 \mathrm{~J} / \mathrm{cm}^{2}$ and $1.39 \mathrm{~J} / \mathrm{cm}^{2}$ were used to create the $\mathrm{SiC}$ and $\mathrm{Al}$ samples, respectively, compared to 0.77 $\mathrm{J} / \mathrm{cm}^{2}$ on Si. The increase in fluence caused an increase in the amount of oxidation and a chemically uniform AN-sphere to form. It is also suggested that the enthalpy of $\mathrm{SiO}_{2}$ and 
$\mathrm{Al}_{2} \mathrm{O}_{3}$ is more negative (more stable) than the base materials which causes this reaction to be favorable.

One theory for why $\mathrm{AN}$-spheres only form on $\mathrm{Si}, \mathrm{SiC}$, and $\mathrm{Al}$ while not on other materials that have been extensively studied with FLSP (e.g. nickel, stainless steel, titanium) is because of the relatively large bandgap of $\mathrm{SiO}_{2}$ and $\mathrm{Al}_{2} \mathrm{O}_{3}$ nanoparticles. Zhang et al. measured bandgaps of $\mathrm{SiO}_{2}$ and $\mathrm{Al}_{2} \mathrm{O}_{3}$ nanoparticles to be $9.1 \mathrm{eV}$ and $8.3 \mathrm{eV}$, respectively [52]. These bandgaps are at least twice as large as the bandgaps of other FLSP studied materials requiring additional photons to be absorbed through multiphoton absorption processes and a majority of the energy to be transmitted or reflected. The absorbed energy is not large enough to ablate the nanoparticles but the absorbed energy can increase the temperature of the nanoparticles enough to sinter them together. In this scenario, the nanoparticles primarily act as sites to scatter the incident laser light and the original material absorbs most of the energy that passes through the oxide layer, thus allowing nanoparticles to continuously aggregate and resist ablation from additional pulses.

\section{Conclusion}

In this paper, the surface morphology and chemical composition of a unique self-organized surface structure, termed AN-spheres, formed through FLSP is reported on $\mathrm{Si}, \mathrm{SiC}$, and $\mathrm{Al}$. The formation mechanisms of AN-spheres is explained based on results from quantified EDX line scans on cross-sections of AN-sphere samples. Although it has not been proven or disproven, it is expected that $\mathrm{AN}$-spheres originate from defects in the base material that nanoparticles aggregate to due to electrostatic forces. Further work to understand the defects that cause the initial aggregation to occur is necessary. Oxide variations within the core of $\mathrm{Si}$ $\mathrm{AN}$-spheres suggest that it is an agglomeration of nanoparticles that sinter together to form a more solid, dense region and a resulting concentric ring structure. After the core region forms, the aggregation of additional nanoparticles during the rastering process cause the $\mathrm{AN}$-sphere to grow larger. Distinct rings form due to sintering of particles when the laser beam is directly illuminating the $\mathrm{AN}$-sphere, which results in an onion-like morphology. The light and dark rings, similar to the core, are agglomerations of nanoparticles. The lowdensity regions are more heavily oxidized due to a larger exposed surface area. The Si ANsphere exhibits the largest variation between the high density and low density rings, which is attributed to the relatively lower fluence required to create the structures when compared to $\mathrm{SiC}$ and $\mathrm{Al}$. In addition to the main focus of this paper, unique particles were dispersed throughout the $\mathrm{SiC} \mathrm{AN}$-sphere. The unique particles were determined to be $\mathrm{SiC}$ nanoparticles that directly fragmented from the base material and silicon nanoparticles with a carbon shell that retarded oxidation.

\section{Acknowledgements}

This work was supported by National Aeronautics and Space Administration (NASA)Experimental Program to Stimulate Competitive Research (EPSCoR) Grant \#NNX13AB17A and the Office of Naval Research (ONR) Contract \#FA4600-12-D-9000-0045. Research was performed in the facilities of the Nebraska Center for Materials and Nanoscience (NCMN) and Nano-Engineering Research Core Facility (NERcF), which are supported by the Nebraska Research Initiative. 


\section{References}

[1]. Vorobyev AY, Guo C, Multifunctional surfaces produced by femtosecond laser pulses, J. Appl. Phys 117 (2015) 33103, 10.1063/1.4905616.

[2]. Tsibidis GD, Fotakis C, Stratakis E, From ripples to spikes: a hydrodynamical mechanism to interpret femtosecond laser-induced self-assembled structures, Phys. Rev. B 92 (2015) 41405, 10.1103/PhysRevB.92.041405.

[3]. Gemini L, Hashida M, Shimizu M, Miyasaka Y, Inoue S, Tokita S, et al., Metal-like selforganization of periodic nanostructures on silicon and silicon carbide under femtosecond laser pulses, J. Appl. Phys 114 (2013) 194903, 10.1063/1.4832829.

[4]. Ahmmed KMT, Ling EJY, Servio P, Kietzig A-M, Introducing a new optimization tool for femtosecond laser-induced surface texturing on titanium, stainless steel, aluminum and copper, Opt. Lasers Eng 66 (2015) 258-268, 10.1016/j.optlaseng.2014.09.017.

[5]. Zuhlke C, Alexander DR, Bruce JC, Ianno NJ, Kamler CA, Yang W, Self assembled nanoparticle aggregates from line focused femtosecond laser ablation, Opt. Express 18 (2010) 4329-4339, 10.1364/OE.18.004329. [PubMed: 20389444]

[6]. Sheehy MA, Winston L, Carey JE, Friend CM, Mazur E, Role of the background gas in the morphology and optical properties of laser-microstructured silicon, Chem. Mater 17 (2005) 3582-3586, 10.1021/cm049029i.

[7]. Phillips KC, Gandhi HH, Mazur E, Sundaram SK, Ultrafast laser processing of materials: a review, Adv. Opt. Photonics 7 (2015) 684, 10.1364/AOP.7.000684.

[8]. Dong Y, Zorman C, Molian P, Femtosecond pulsed laser micromachining of single crystalline 3C$\mathrm{SiC}$ structures based on a laser-induced defect-activation process, J. Micromech. Microeng 13 (2003) 680-685, 10.1088/0960-1317/13/5/320.

[9]. Singh N, Alexander DR, Schiffern J, Doerr D, Femtosecond laser production of metal surfaces having unique surface structures that are broadband absorbers, J. Laser Appl 18 (2006) 242, 10.2351/1.2227017.

[10]. Vorobyev AY, Guo C, Enhanced absorptance of gold following multipulse femtosecond laser ablation, Phys. Rev. B 72 (2005) 195422, 10.1103/PhysRevB.72.195422.

[11]. Kruse CM, Anderson T, Wilson C, Zuhlke C, Alexander D, Gogos G, et al., Enhanced poolboiling heat transfer and critical heat flux on femtosecond laser processed stainless steel surfaces, Int. J. Heat Mass Transf 82 (2015) 109-116, 10.1016/j.ijheatmasstransfer.2014.11.023.

[12]. Kruse C, Anderson T, Wilson C, Zuhlke C, Alexander D, Gogos G, et al., Extraordinary shifts of the leidenfrost temperature from multiscale micro/nanostructured surfaces, Langmuir (2013), 10.1021/la401936w.

[13]. Kruse C, Tsubaki A, Zuhlke C, Anderson T, Alexander D, Gogos G, et al., Secondary pool boiling effects, Appl. Phys. Lett 108 (2016) 51602, 10.1063/1.4941081.

[14]. Vorobyev AY, Guo C, Laser turns silicon superwicking, Opt. Express 18 (2010) 6455-6460, http://www.ncbi.nlm.nih.gov/pubmed/20389669 (Accessed June 1, 2016). [PubMed: 20389669]

[15]. Long J, Zhong M, Fan P, Gong D, Zhang H, Wettability conversion of ultrafast laser structured copper surface, J. Laser Appl 27 (2015) S29107, 10.2351/1.4906477.

[16]. Wu B, Zhou M, Li J, Ye X, Li G, Cai L, Superhydrophobic surfaces fabricated by microstructuring of stainless steel using a femtosecond laser, Appl. Surf. Sci 256 (2009) 61-66, 10.1016/j.apsusc.2009.07.061.

[17]. Ahmmed K, Grambow C, Kietzig A-M, Fabrication of micro/nano structures on metals by femtosecond laser micromachining, Micromachines 5 (2014) 1219-1253, 10.3390/mi5041219.

[18]. Lehr J, Kietzig A-M, Production of homogenous micro-structures by femtosecond laser micromachining, Opt. Lasers Eng 57 (2014) 121-129, 10.1016/j.optlaseng.2014.01.012.

[19]. Vorobyev AY, Guo C, Direct femtosecond laser surface nano/microstructuring and its applications, Laser Photon Rev 7 (2013) 385-407, 10.1002/lpor.201200017.

[20]. Zuhlke C, Anderson TP, Alexander DR, Fundamentals of layered nanoparticle covered pyramidal structures formed on nickel during femtosecond laser surface interactions, Appl. Surf. Sci 21 (2013) 8460-8473, 10.1016/j.apsusc.2013.07.002. 
[21]. Zuhlke C, Anderson TP, Alexander DR, Formation of multiscale surface structures on nickel via above surface growth and below surface growth mechanisms using femtosecond laser pulses, Opt. Express 21 (2013) 8460-8473, 10.1364/OE.21.008460. [PubMed: 23571936]

[22]. Zuhlke C, Anderson TP, Alexander DR, Comparison of the structural and chemical composition of two unique micro/nanostructures produced by femtosecond laser interactions on nickel, Appl. Phys. Lett 103 (2013) 121603, 10.1063/1.4821452.

[23]. Peng E, Tsubaki A, Zuhlke CA, Wang M, Bell R, Lucis MJ, et al., Micro/nanostructures formation by femtosecond laser surface processing on amorphous and polycrystalline Ni60Nb40, Appl. Surf. Sci 396 (2017) 1170-1176, 10.1016/j.apsusc.2016.11.107.

[24]. Peng E, Tsubaki A, Zuhlke CA, Wang M, Bell R, Lucis MJ, et al., Experimental explanation of the formation mechanism of surface mound-structures by femtosecond laser on polycrystalline Ni60Nb40, Appl. Phys. Lett 108 (2016) 31602, 10.1063/1.4939983.

[25]. Ling EJY, Saïd J, Brodusch N, Gauvin R, Servio P, Kietzig A-M, Investigating and understanding the effects of multiple femtosecond laser scans on the surface topography of stainless steel 304 and titanium, Appl. Surf. Sci 353 (2015) 512-521, 10.1016/j.apsusc.2015.06.137.

[26]. Kam DH, Bhattacharya S, Mazumder J, Control of the wetting properties of an AISI 316L stainless steel surface by femtosecond laser-induced surface modification, J. Micromech. Microeng 22 (2012) 105019, 10.1088/0960-1317/22/10/105019.

[27]. Povarnitsyn ME, Itina TE, Hydrodynamic modeling of femtosecond laser ablation of metals in vacuum and in liquid, Appl. Phys. A 117 (2014) 175-178, 10.1007/s00339-014-8319-1.

[28]. Povarnitsyn ME, Itina TE, Levashov PR, Khishchenko KV, Mechanisms of nanoparticle formation by ultra-short laser ablation of metals in liquid environment, Phys. Chem. Chem. Phys 15 (2013) 3108-3114, 10.1039/c2cp42650a. [PubMed: 23319115]

[29]. Shugaev MV, Wu C, Armbruster O, Naghilou A, Brouwer N, Ivanov DS, et al., Fundamentals of ultrafast laser-material interaction, MRS Bull 41 (2016) 960-968, 10.1557/mrs.2016.274.

[30]. Ullmann M, Friedlander SK, Schmidt-Ott A, Nanoparticle formation by laser ablation, J. Nanopart. Res 4 (2002) 499-509, 10.1023/A.1022840924336.

[31]. Wu C, Crouch CH, Zhao L, Mazur E, Visible luminescence from silicon surfaces microstructured in air, Appl. Phys. Lett 81 (2002) 1999, 10.1063/1.1504868.

[32]. Jiménez E, Abderrafi K, Abargues R, Valdés JL, Martínez-Pastor JP, Laser-ablation-induced synthesis of SiO2-capped noble metal nanoparticles in a single step, Langmuir 26 (2010) 74587463, 10.1021/la904179x. [PubMed: 20187628]

[33]. Kumar B, Thareja RK, Laser ablated copper plasmas in liquid and gas ambient, Phys. Plasmas 20 (2013) 53503, 10.1063/1.4807041.

[34]. Wu C, Ren H, Liu T, Ma R, Yang H, Jiang H, et al., Laser-induced dissociation and explosion of methane and methanol, J. Phys. B At. Mol. Opt. Phys 35 (2002) 2575-2582, 10.1088/0953-4075/35/11/315.

[35]. Maisterrena-Epstein R, Camacho-López S, Escobar-Alarcón L, Camacho-López MA, Nanosecond laser ablation of bulk Al, Bronze, and $\mathrm{Cu}$ : ablation rate saturation and laser- induced oxidation, Superf. vacío 20 (2007) 1-5.

[36]. Semaltianos NG, Nanoparticles by laser ablation, Crit. Rev. Solid State Mater. Sci 35 (2010) 105-124, 10.1080/10408431003788233.

[37]. Murray M, Jose G, Richards B, Jha A, Femtosecond pulsed laser deposition of silicon thin films, Nanoscale Res. Lett 8 (2013) 272, 10.1186/1556-276X-8-272. [PubMed: 23758871]

[38]. Bourquard F, Maddi C, Donnet C, Loir A-S, Barnier V, Wolski K, et al., Effect of nitrogen surrounding gas and plasma assistance on nitrogen incorporation in a-C:N films by femtosecond pulsed laser deposition, Appl. Surf. Sci 374 (2016) 104-111, 10.1016/j.apsusc.2015.10.039.

[39]. Amendola V, Meneghetti M, What controls the composition and the structure of nanomaterials generated by laser ablation in liquid solution? Phys Chem. Chem. Phys 15 (2013) 3027-3046, 10.1039/c2cp42895d. [PubMed: 23165724]

[40]. Semaltianos NG, Logothetidis S, Perrie W, Romani S, Potter RJ, Edwardson SP, et al., Silicon nanoparticles generated by femtosecond laser ablation in a liquid environment, J. Nanopart. Res 12 (2009) 573-580, 10.1007/s11051-009-9625-y. 
[41]. Tull BR, Carey JE, Sheehy MA, Friend C, Mazur E, Formation of silicon nanoparticles and weblike aggregates by femtosecond laser ablation in a background gas, Appl. Phys. A 83 (2006) 341346, 10.1007/s00339-006-3502-7.

[42]. Eliezer S, Eliaz N, Grossman E, Fisher D, Gouzman I, Henis Z, et al., Synthesis of nanoparticles with femtosecond laser pulses, Phys. Rev. B 69 (2004) 144119, 10.1103/PhysRevB.69.144119.

[43]. Zamiri R, Azmi BZ, Sadrolhosseini AR, Ahangar HA, Zaidan AW, Mahdi MA, Preparation of silver nanoparticles in virgin coconut oil using laser ablation, Int. J. Nanomed 6 (2011) 71-75, 10.2147/IJN.S14005.

[44]. Straumanis ME, Aka EZ, Lattice Parameters, Coefficients of thermal expansion, and atomic weights of purest silicon and germanium, J. Appl. Phys 23 (1952) 330-334, 10.1063/1.1702202.

[45]. Yamaguchi M, Ueno S, Kumai R, Kinoshita K, Murai T, Tomita T, et al., Raman spectroscopic study of femtosecond laser-induced phase transformation associated with ripple formation on single-crystal SiC, Appl. Phys. A Mater. Sci. Process 99 (2010) 23-27, 10.1007/ s00339-010-5569-4.

[46]. Ma HL, Yang JY, Dai Y, Zhang YB, Lu B, Ma GH, Raman study of phase transformation of TiO2 rutile single crystal irradiated by infrared femtosecond laser, Appl. Surf. Sci 253 (2007) 74977500, 10.1016/j.apsusc.2007.03.047.

[47]. Roundy D, Krenn CR, Cohen ML, Morris JW, Ideal shear strengths of fcc aluminum and copper, Phys. Rev. Lett 29 (1999).

[48]. Harris AJ, Vaughan B, Yeomans JA, Smith PA, Burnage ST, Surface preparation of silicon carbide for improved adhesive bond strength in armour applications, J. Eur. Ceram. Soc 33 (2013) 2925-2934, 10.1016/j.jeurceramsoc.2013.05.026.

[49]. Vorobyev AY, Guo C, Nanochemical effects in femtosecond laser ablation of metals, Appl. Phys. Lett 102 (2013), 10.1063/1.4793521.

[50]. Tomita T, Okada T, Kawahara H, Kumai R, Matsuo S, Hashimoto S, et al., Microscopic analysis of carbon phases induced by femtosecond laser irradiation on single-crystal SiC, Appl. Phys. A 100 (2010) 113-117, 10.1007/s00339-010-5786-x.

[51]. Koten MA, Mukherjee P, Shield JE, Core-shell nanoparticles driven by surface energy differences in the co-Ag, W-Fe, and Mo-Co systems, Part. Part. Syst. Charact 32 (2015) 848-853, 10.1002/ ppsc. 201500019.

[52]. Zhang H, Ji Z, Xia T, Meng H, Low-Kam C, Liu R, et al., Use of metal oxide nanoparticle band gap to develop a predictive paradigm for oxidative stress and acute pulmonary inflammation, ACS Nano 6 (2012) 4349-4368, 10.1021/nn3010087. [PubMed: 22502734] 


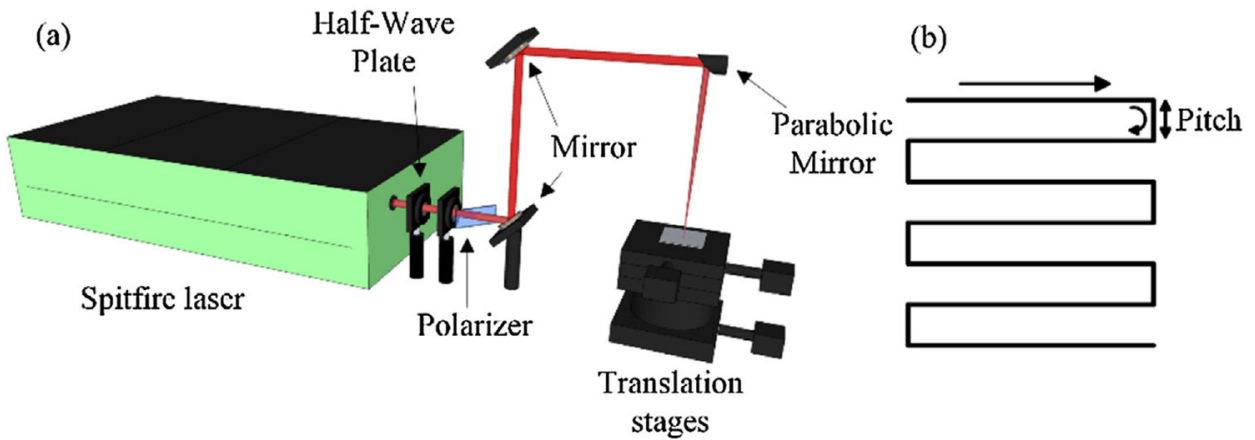

Fig. 1.

(a) Femtosecond laser experimental setup and (b) raster scanning pattern 


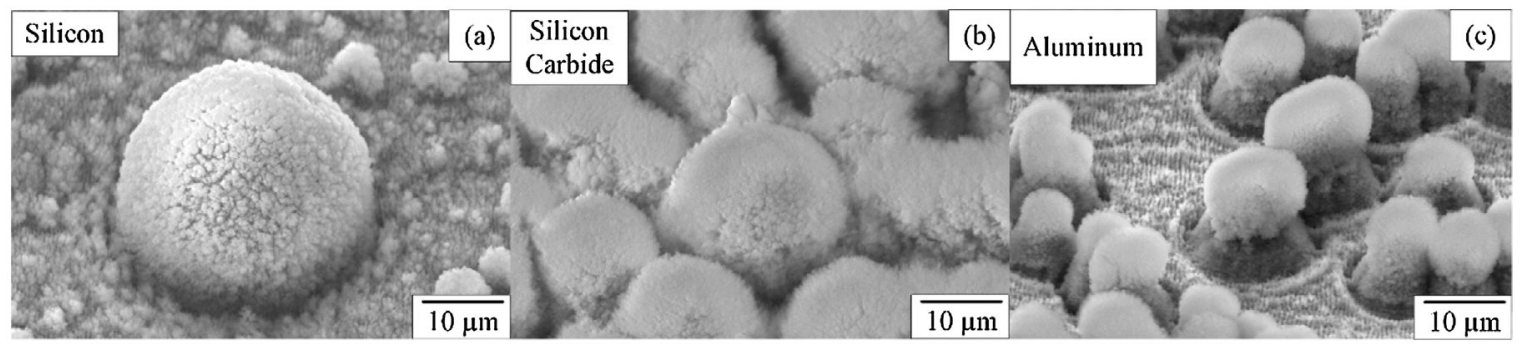

Fig. 2.

Scanning electron micrographs showing the morphologies of aggregated nanoparticlespheres on: (a) $\mathrm{Si}$, (b) $\mathrm{SiC}$, and (c) Al. 


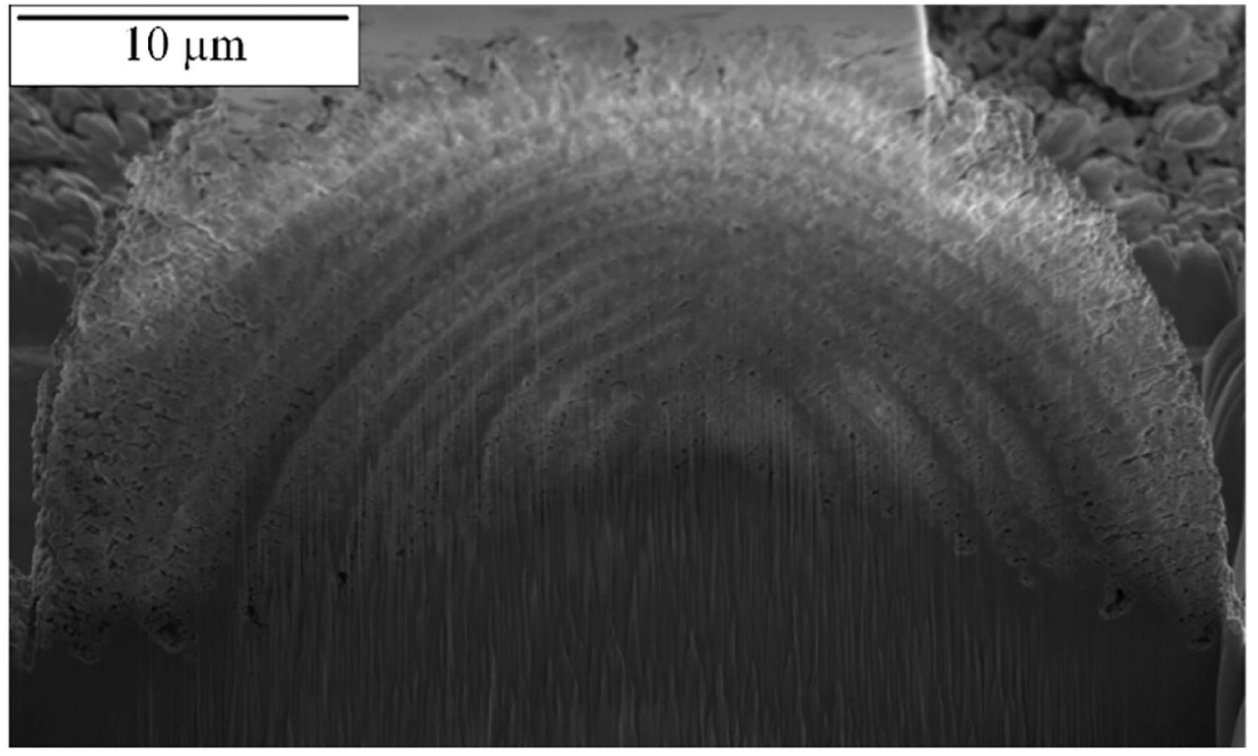

Fig. 3.

Scanning electron micrograph showing the internal structure of a Si AN-sphere. Crosssectioning was accomplished using focused ion beam milling. 


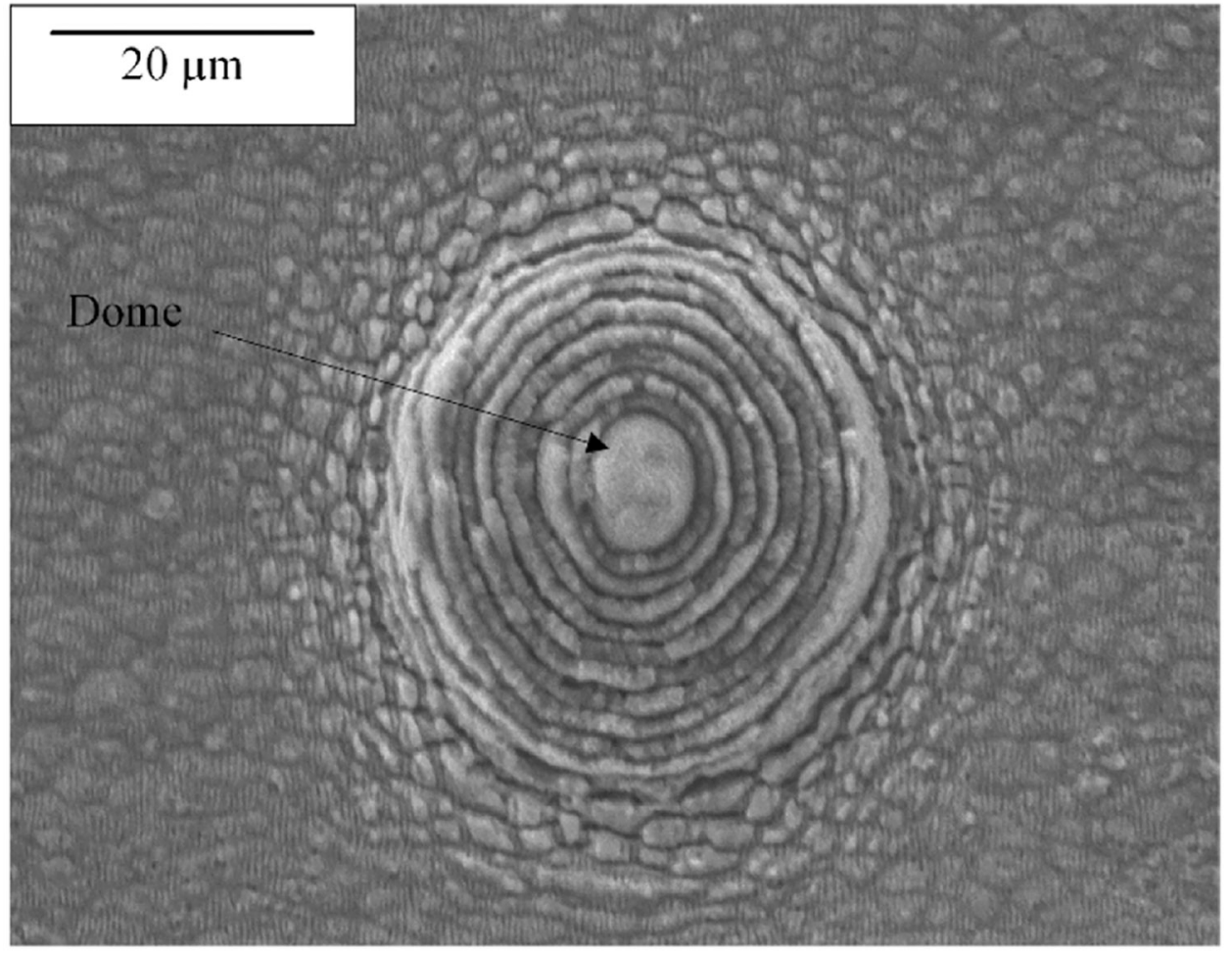

Fig. 4.

$\mathrm{Si} \mathrm{AN}$-sphere shell structure viewed at $0^{\circ}$ in SEM. 

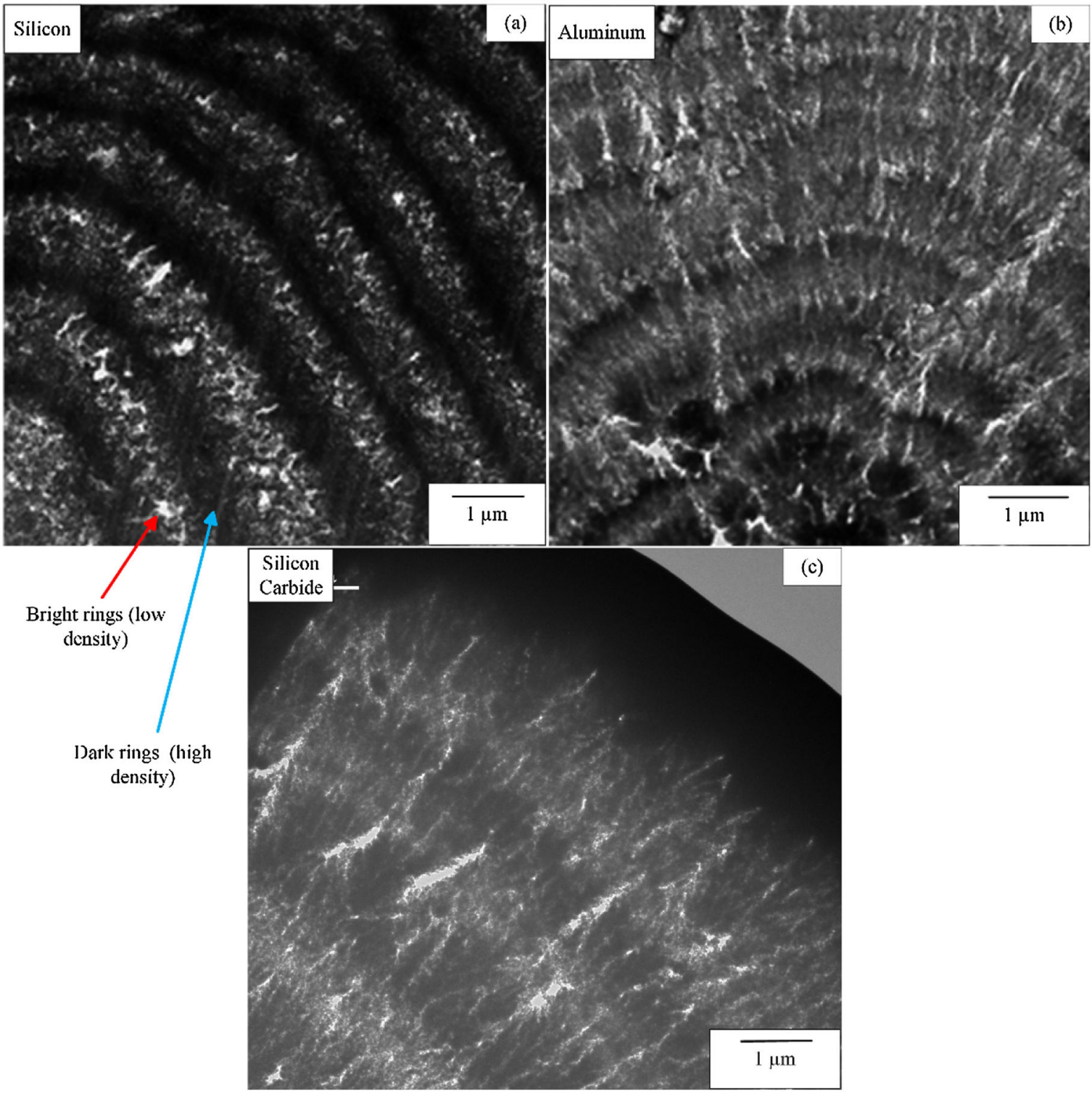

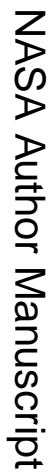

Fig. 5.

Bright field TEM images of AN-sphere ring structure on (a) Si, (b) Al, and (c) SiC. 


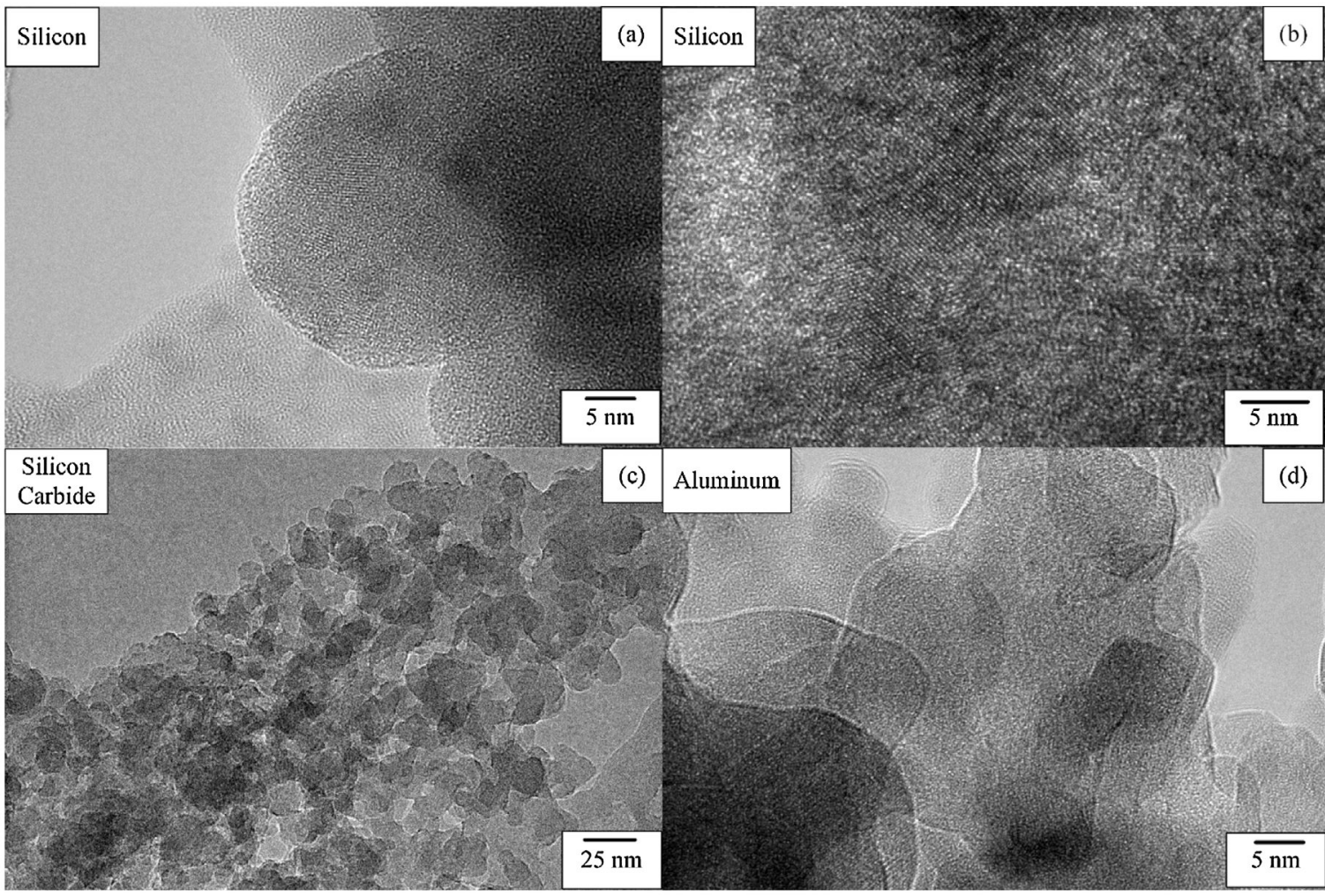

Fig. 6.

TEM images of AN-sphere nanoparticles on (a-b) Si, (c) SiC, and (d) Al. 


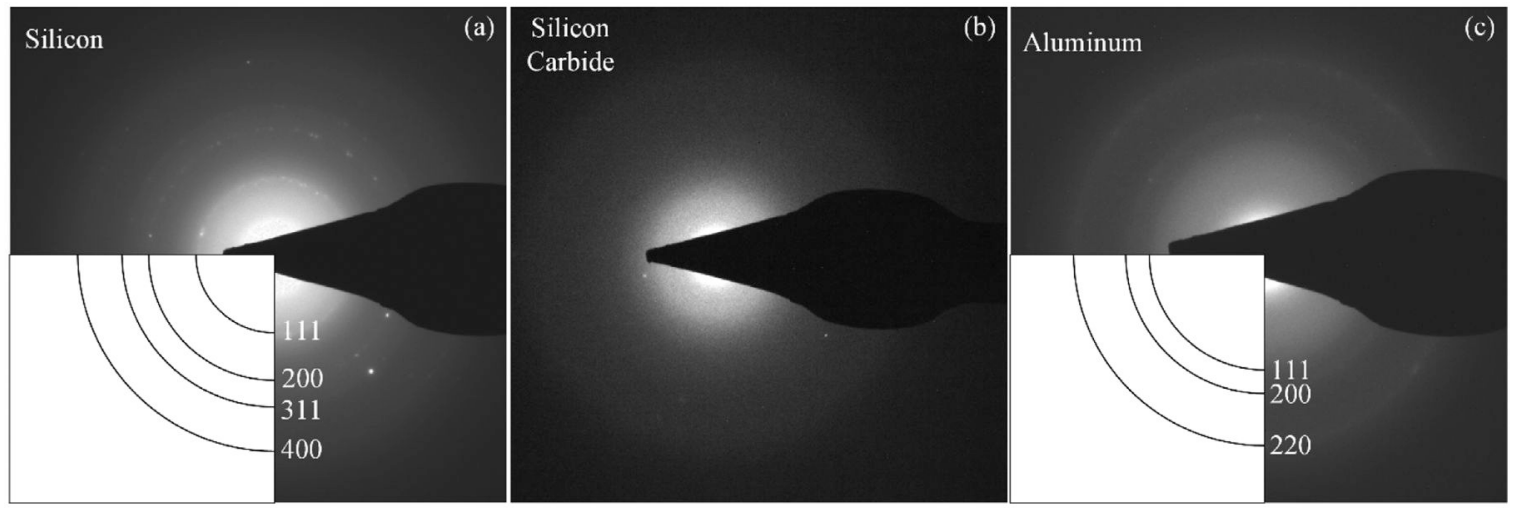

Fig. 7.

SAD patterns for AN-spheres on (a) $\mathrm{Si}$, (b) $\mathrm{SiC}$, and (c) Al. 


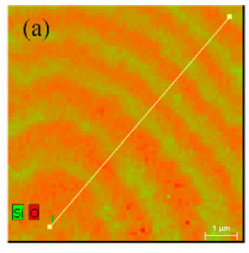

(b)

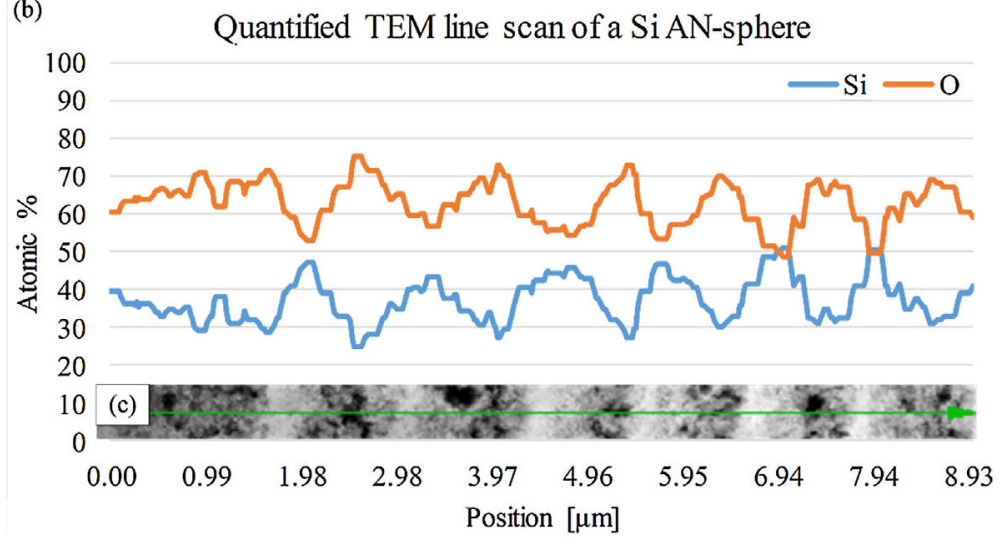

Fig. 8.

(a) Elemental map of a Si AN-sphere, (b) quantified EDX line scan, and (c) HAADF-STEM image. 


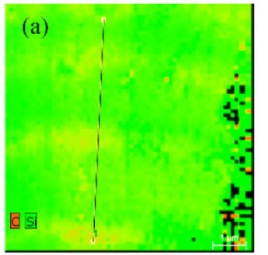

(b)

Quantified TEM line scan of a SiC AN-sphere

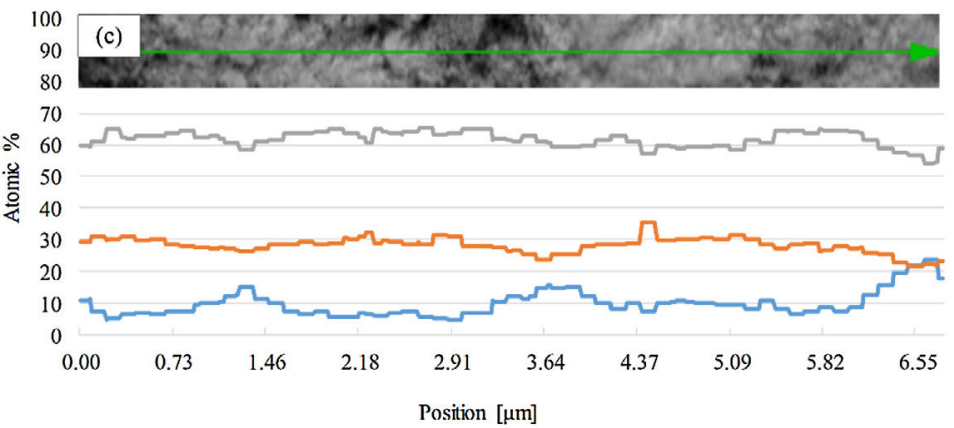

Fig. 9.

(a) Elemental map of a SiC AN-sphere, (b) quantified EDX line scan, and (c) HAADFSTEM image. 


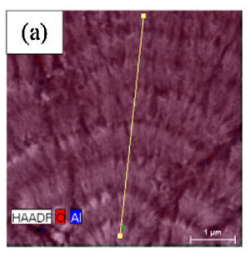

(b) Quantificd TEM line scan of an $\mathrm{Al} \mathrm{AN}$-sphere

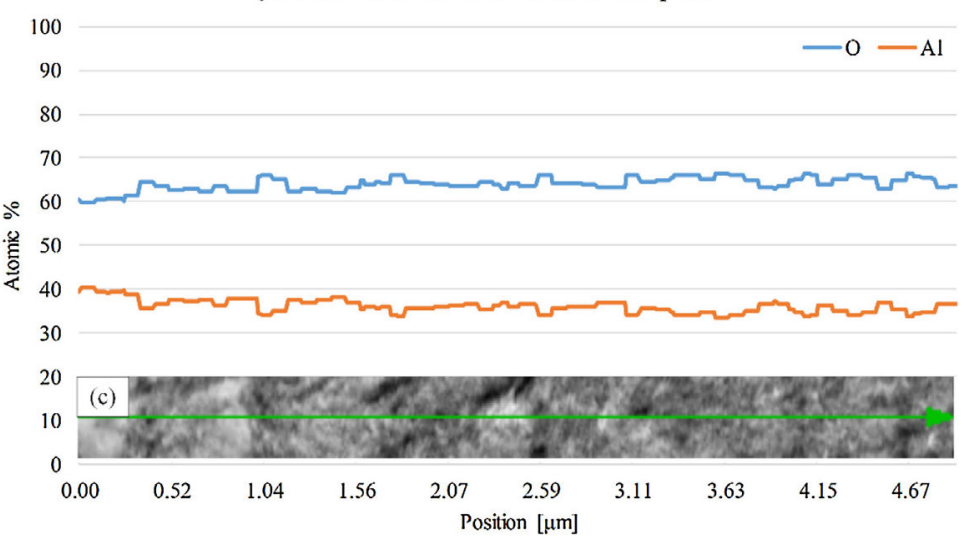

Fig. 10.

(a) Elemental map of an Al AN-sphere, (b) quantified EDX line scan, and (c) HAADFSTEM image. 


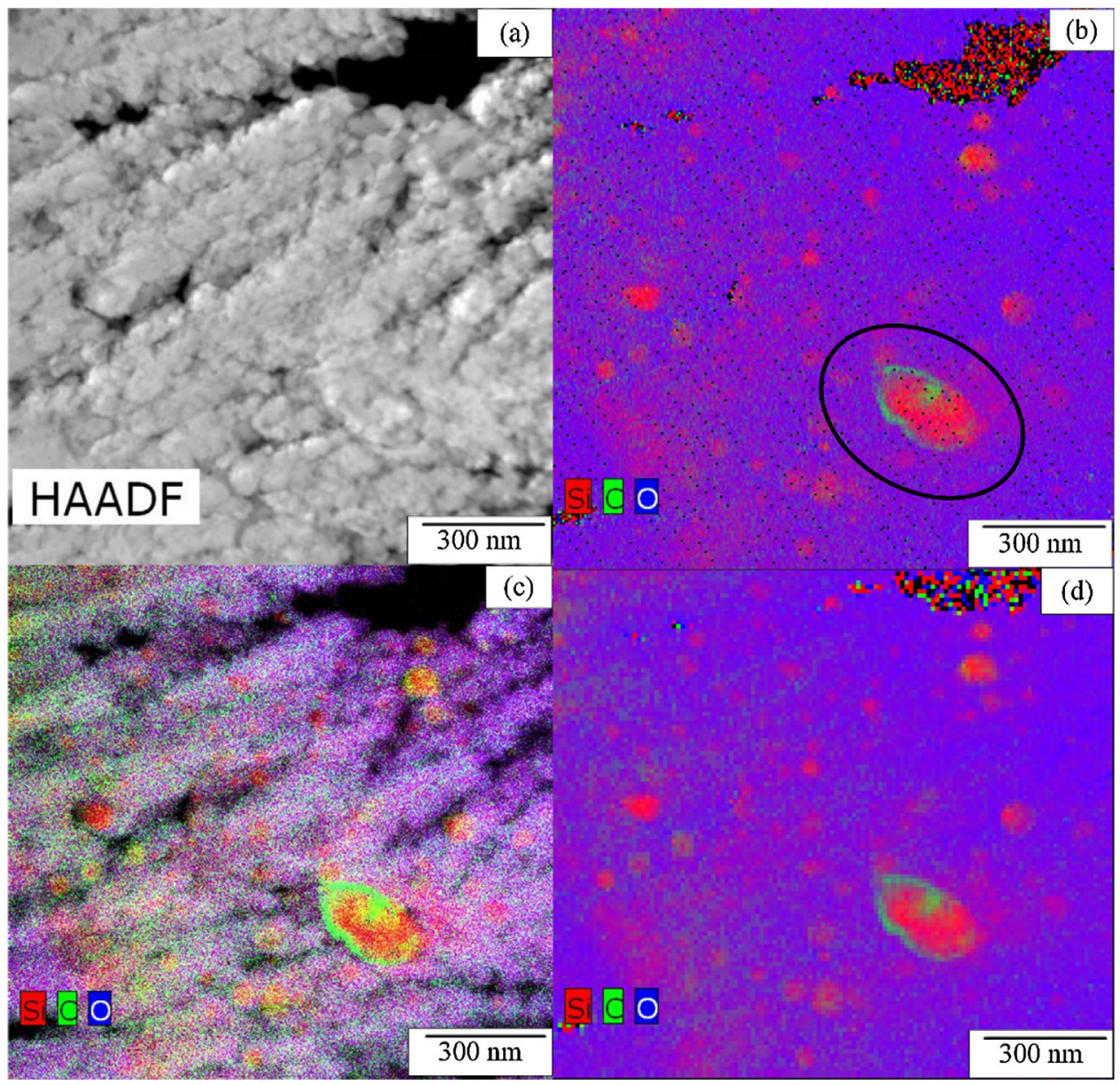

Fig. 11.

HAADF-STEM elemental maps of a nanoparticle on a Sic AN-sphere. 


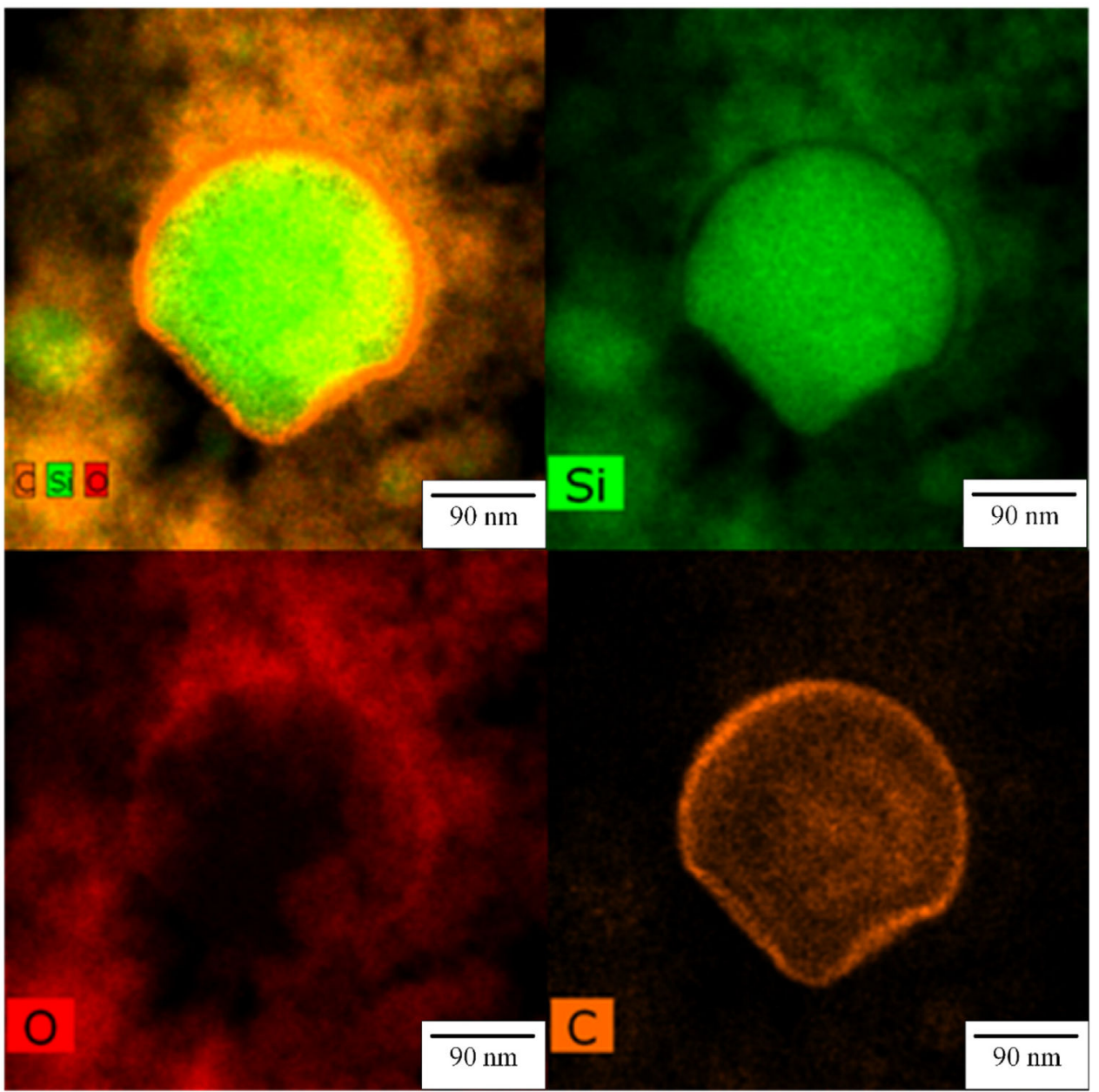

Fig. 12.

Elemental maps of a nanoparticle on a $\mathrm{SiC} \mathrm{AN-sphere.}$ 


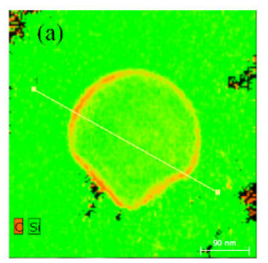

(b)

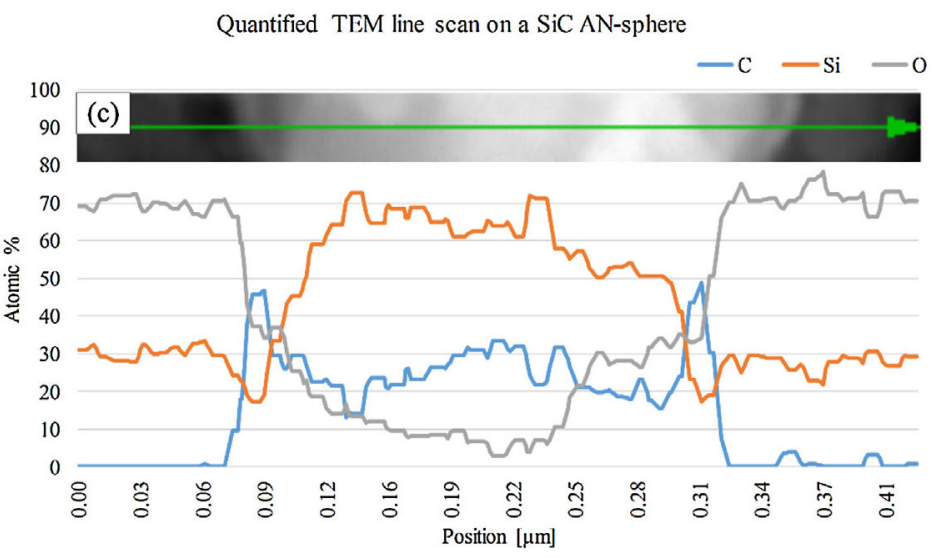

Fig. 13.

(a) Elemental map of the carbon-shell nanoparticle, (b) quantified EDX line scan, and (c) HAADF-STEM image. 


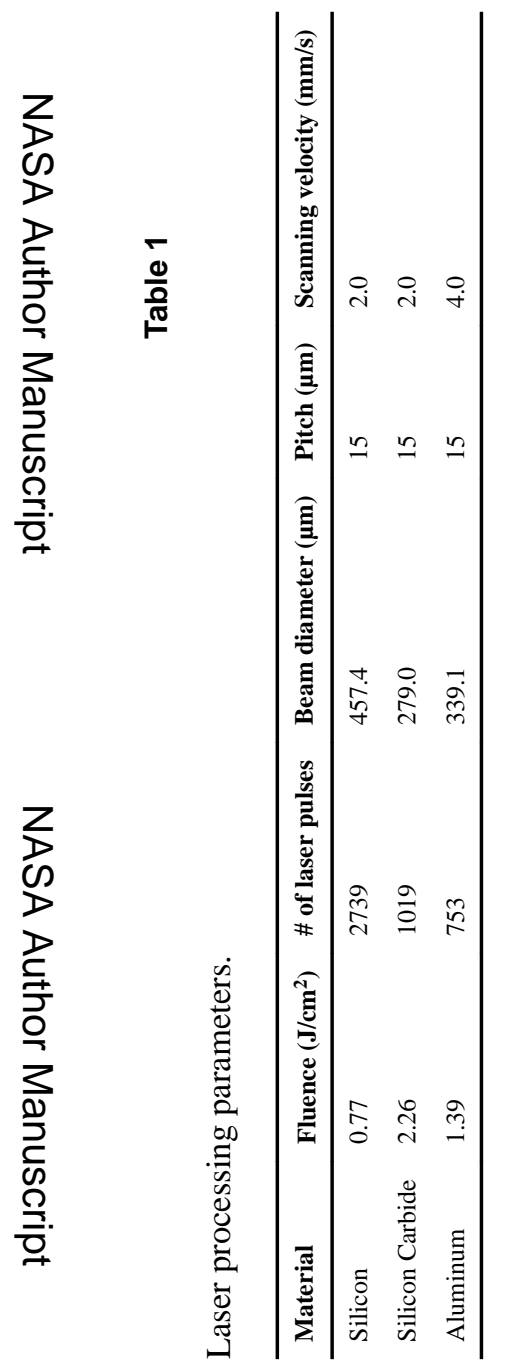

Appl Surf Sci. Author manuscript; available in PMC 2018 November 06. 
Table 2

EDX analysis of $\mathrm{AN}$-spheres on $\mathrm{Si}, \mathrm{SiC}$, and $\mathrm{Al}$.

\begin{tabular}{lllll}
\hline AN-sphere substrate & \multicolumn{4}{l}{ Atomic Percent (\%) } \\
& Carbon & Oxygen & Silicon & Aluminum \\
\hline Silicon & $9.86 \pm 1.25$ & $59.80 \pm 4.04$ & $30.34 \pm 0.83$ & - \\
Silicon Carbide & $4.10 \pm 0.62$ & $66.53 \pm 5.02$ & $29.36 \pm 0.84$ & - \\
Aluminum & $8.76 \pm 1.12$ & $57.02 \pm 4.32$ & - & $34.23 \pm 1.24$ \\
\hline
\end{tabular}

